\title{
Negotiating a Stable Government: An Application of Bargaining Theory to a Coalition Formation Model
}

\author{
Agnieszka Rusinowska • Harrie De Swart
}

Published online: 12 February 2008

(C) Springer Science+Business Media B.V. 2008

\begin{abstract}
In this paper, we apply bargaining theory to a certain model of coalition formation. The notions of a feasible government and a stable government are central in the model considered. By a government, we mean a pair consisting of a majority coalition and a policy supported by this coalition. The aim of this paper is to establish which stable government should be created if more than one stable government exists or, in case there is no stable one, which feasible government should be formed if more than one feasible government exists. Several bargaining procedures leading to the choice of one stable (or feasible) government are proposed. We define bargaining games in which only parties belonging to at least one stable (or feasible) government bargain over the creation of a government. We consider different bargaining costs. We investigate subgame perfect equilibria of the bargaining games defined. It turns out that the prospects of a party depend on the procedure applied, and on the bargaining costs assumed. We also apply the coalition formation model to the Polish Parliament after the 2001 elections and apply the different bargaining games for the creation of a government to this example.
\end{abstract}

Keywords Stable government $\cdot$ Bargaining game $\cdot$ Subgame perfect equilibrium

\section{Introduction}

In the literature, one can find many works concerning coalition formation theory (see, for instance; Austen-Smith and Banks 1988, 1990; Axelrod 1970; Baron and Ferejohn 1989; van Deemen 1991, 1997; Grofman 1982; Kahan and Rapoport 1984; Kirchsteiger and Puppe

\footnotetext{
A. Rusinowska $(\bowtie)$

CNRS - Université Lumière Lyon 2, GATE, 93 Chemin des Mouilles, B.P. 167, 69131 Ecully Cedex, France

e-mail: rusinowska@gate.cnrs.fr

H. De Swart

Department of Philosophy, Tilburg University, P.O. Box 90153, 5000 LE Tilburg, The Netherlands e-mail: H.C.M.deSwart@uvt.nl
} 
1997; Laver and Shepsle 1996; Peleg 1981; Schofield 1993; de Swaan 1973; de Vries 1999). An alternative model of coalition formation has recently been presented by van der Rijt (2000). It belongs to the class of coalition theories that take policy preferences of parties into consideration. A generalization of the model defined by van der Rijt has been proposed in Rusinowska et al. (2005), and this generalized model is our point of departure here. In this paper, we present an application of bargaining theory to the coalition formation model introduced in Rusinowska et al. (2005). The central notions of the model are the notions of a feasible government and a stable government. We consider the situation in which more than one stable government exists or no stable government exists, but there are at least two feasible governments. In order to choose only one stable (or feasible) government, parties may negotiate with each other to create a government. To this end, some bargaining games are defined, and subgame perfect equilibria of these games are investigated. In all bargaining games analyzed, only parties belonging to at least one stable (or feasible) government are involved in bargaining over the creation of a government. The games considered differ from each other with respect to the bargaining procedure. In one of these games, only one party, for instance the strongest one, makes offers to the others. Moreover, we consider two kinds of games differing with respect to the bargaining costs. In the first kind, we assume one constant bargaining cost satisfying a certain condition. In the second kind of games, a sequence of bargaining costs is introduced, where the bargaining cost may be different in each period of the game. The prospects of a party depend on the procedure applied, and on the bargaining costs assumed. We present a theoretical example concerning the Polish Parliament after the 2001 elections. The example illustrates the notions defined in the generalized model (Rusinowska et al. 2005). In our example, we find more than one stable government. Moreover, we apply the bargaining games defined to the Polish Parliament.

The paper is organized as follows. In Sect. 2, we briefly describe the generalized model of coalition formation (Rusinowska et al. 2005) to which we apply bargaining theory. In Sect. 3 , the bargaining games for choosing a government are introduced. In Sect. 4, we present an example in which we apply the coalition formation model and the bargaining games to the Polish Parliament after the 2001 elections. Finally, we present our conclusions in Sect. 5.

\section{The Model of Coalition Formation}

Let $N=\{1, \ldots, n\}$ be the set of political parties in parliament, and let $w_{i}$ denote the number of seats received by party $i \in N . w_{i}$ is called the weight of party $i$. Let $q$ be the quotum. A coalition $S$ is a subset of $N$. A coalition $S$ is winning if the sum of the weights of the parties in $S$ is at least $q$. Moreover, let $W$ denote the set of all winning coalitions. The model concerns the creation of a government by a winning coalition. It is assumed that there are some independent policy issues, say $1, \ldots, M$, on which a government has to decide. Let $P$ denote the set of all policies $p=\left(p_{1}, \ldots, p_{M}\right)$ where $p_{j}$ is the sub-policy on issue $j$.

A government is defined as a pair $g=(S, p)$, where $S$ is a winning coalition and $p$ is a policy. Hence, the set $G$ of all governments is defined as

$$
G:=\{(S, p) \mid S \in W \wedge p \in P\} .
$$

Each party has preferences concerning all (winning) coalitions and all policies. More precisely, let $d_{0}, \ldots, d_{L}$ be degrees of desirability, where $d_{0}$ means just acceptable (desirable of degree 0 ) and $d_{L}$ is the highest degree of desirability: $0=d_{0}<d_{1}<\cdots<d_{L}=1$. We assume that for each party $i \in N$ there is a utility function $U_{i}$ that assigns to each winning 
coalition $S$ a value $U_{i}(S)$ in $\left\{-(M+1), d_{0}, d_{1}, \ldots, d_{L}\right\}$ and that assigns to each sub-policy $p_{j}$ on issue $j$ a value $U_{i}\left(p_{j}\right) \in\left\{-(M+1), d_{0}, d_{1}, \ldots, d_{L}\right\}$.

The utility $U_{i}(g)$ of a government $g=(S, p)$ is defined by

$$
U_{i}(S, p)=U_{i}(S)+U_{i}(p)=U_{i}(S)+\sum_{j=1}^{M} U_{i}\left(p_{j}\right) .
$$

As noticed in Rusinowska et al. (2005), for each government $(S, p), U_{i}(S, p)<0$ if and only if $U_{i}(S)=-(M+1)$ or $U_{i}\left(p_{j}\right)=-(M+1)$ for at least one $j \in\{1, \ldots, M\}$.

In Roubens et al. (2006) we use the MacBeth software to determine the utilities $U_{i}(S)$ and $U_{i}(p)$.

A coalition $S$ is called feasible if it is acceptable (i.e., $U_{i}(S) \geq 0$ ) to all its members $i \in S$. A policy $p$ is feasible for a given coalition $S$ if it is acceptable to all members of that coalition, i.e., for all $i \in S, U_{i}\left(p_{j}\right) \geq 0$ for all $j=1, \ldots, M$. A government $g=(S, p)$ is feasible if $S$ is a feasible coalition and $p$ is a feasible policy for $S$. By $F G$ we denote the set of all feasible governments:

$$
F G=\{(S, p) \in G \mid(S, p) \text { is feasible }\} .
$$

The central notion of the model introduced in Rusinowska et al. (2005) is the notion of stability. A feasible government $h=(S, p) \in F G$ dominates a feasible government $g \in F G$ (denoted as $h \succ g$ ) if the property

$$
\left(\forall i \in S: U_{i}(h) \geq U_{i}(g)\right) \wedge\left(\exists i \in S: U_{i}(h)>U_{i}(g)\right)
$$

holds. A feasible government is said to be stable if it is dominated by no feasible government, i.e.,

$$
g \text { is stable }:=\neg \exists h \in F G[h \succ g]
$$

By $S G$ we denote the set of all (feasible) stable governments. In Rusinowska et al. (2005), necessary and sufficient conditions for the existence and the uniqueness of a stable government are investigated. Moreover, in the same paper the authors introduce some alternative definitions of 'stability', and establish the relations between the new notions of 'stability' and the chosen one. In the present paper, we decide for the definition of a stable government given by (5), which we find the most natural definition of stability.

Note that the relation of dominance defined in (4) is not necessarily acyclic, because only the members of coalition $S$ in government $h$ are considered. Consequently, it is possible that no stable government exists in the sense of definition (5).

\section{Creating a Government}

If there is only one stable government, this unique stable government is formed. It is clear that, in our generalized model (Rusinowska et al. 2005), more than one stable government may exist. In such situations, the question arises which stable government should be created. It is also possible that no stable government exists. In that case the question is which feasible government to form if there is more than one.

In this paper, we propose some bargaining procedures leading to the choice of one stable (respectively, feasible) government if there is more than one. Our bargaining games are different from the one introduced by Rubinstein (Fishburn and Rubinstein 1982; Osborne and Rubinstein 1990; Rubinstein 1982) in several respects, as our bargaining serves a different 
purpose. As in many papers on bargaining theory, we look for subgame perfect equilibria of the bargaining games. Let $C G$ be the set $S G$ of all stable governments if there is more than one, and the set $F G$ of all feasible governments if there is no stable government, but more than one feasible government.

$$
C G= \begin{cases}S G & \text { if }|S G|>1 \\ F G & \text { if }|S G|=0 \text { and }|F G|>1\end{cases}
$$

In our games, all parties belonging to at least one government from $C G$ bargain over the creation of one government. Parties which are not members of a government from $C G$ do not participate in the negotiations. Let $N^{C G}$ be the set of all parties involved in at least one government from $C G$. Let $k^{C G}$ be the number of parties in $N^{C G}$, i.e., $k^{C G}=\left|N^{C G}\right|$.

Let $\overline{N^{C G}}$ be an ordered list $\left(n_{1}, \ldots, n_{k} C G\right)$ of all parties involved in at least one government from $C G$, where the order is given, for instance, by the number of seats or the number of votes.

\subsection{Choosing a Government}

In this subsection, we define several bargaining games in which parties from $N^{C G}$ bargain over the choice of one government from $C G$.

We call two governments $g$ and $g^{\prime}$ in $N^{C G}$ equivalent iff $U_{i}(g)=U_{i}\left(g^{\prime}\right)$ for each $i \in N^{C G}$. We assume there are only finitely many non equivalent governments in $C G$.

GAME $A$ is defined by the following bargaining rules:

1. The set of players in this game is $N^{C G}$.

2. A party $i \in N^{C G}$, when submitting an offer, can propose only one government from $C G$ such that this party belongs to it.

3. Rejecting an offer causes a following period to start.

4. A party $i \in N^{C G}$ cannot propose a government which has already been proposed before. Then, since the set $C G$ is finite, the extensive form of our bargaining game is finite. Parties will not negotiate longer than $|C G|$ periods.

5. The bargaining procedure is as follows. The first party $n_{1}$ in the sequence $\overline{N^{C G}}$ proposes in period 1 a certain $g^{(1)}=\left(S^{(1)}, p^{(1)}\right) \in C G$ such that $n_{1} \in S^{(1)}$. Next, the party belonging to $S^{(1)}$ having the 'strongest' (the earliest) position in $\overline{N^{C G}}$ from among all members of $S^{(1)}$ excluding $n_{1}$ can either accept or reject the offer. Let us denote this party by $n_{r}$ (for some $r=2, \ldots, k^{C G}$ ). If $n_{r}$ rejects $g^{(1)}$, then period 2 starts and party $n_{r}$ proposes a new government $g^{(2)}=\left(S^{(2)}, p^{(2)}\right) \in C G$ which will again be confronted with its members. If $n_{r}$ accepts $g^{(1)}$ and if $S^{(1)}$ consists of only two parties $\left(n_{1}\right.$ and $\left.n_{r}\right)$, the game is over and $g^{(1)}$ is chosen, but if $S^{(1)}$ has more than two members, period 1 continues and these members, starting again with the 'strongest' one (excluding $n_{1}$ and $n_{r}$ ), have to react by saying either 'yes' or 'no'. If a government is accepted by all its members, the game is over and this government is chosen. Rejecting a government causes the rejecting party to submit its own 'proper' offer in the next period. By 'proper', we mean that this government has not been proposed before and that this rejecting party is one of its members. According to this procedure, there is always a period $1 \leq t \leq|C G|$ such that no new government can be proposed anymore, because all governments from $C G$ have already been proposed before or/and the reacting party is not a member of another government from $C G$ and hence cannot make a new proposal. In such situations, the last government proposed is chosen. In this way, the negotiations will always result in the choice of one government from $C G$. 
6. In general, the result of our bargaining game is a pair $(g, T)$, where $g \in C G$ is the government agreed upon and $1 \leq T \leq|C G|$ is the period in which the agreement has been reached.

7. The payment of party $i \in N^{C G}$, if the result $(g, T)$ is reached, is given by

$$
U_{i}(g, T)=U_{i}(g)-c \cdot(T-1)
$$

where $c>0$ is the fixed bargaining cost satisfying the following condition: for all $i \in N^{C G}$ and for all $g, g^{\prime} \in C G$

$$
U_{i}(g)>U_{i}\left(g^{\prime}\right) \Longrightarrow U_{i}(g)-c \cdot(|C G|-1)>U_{i}\left(g^{\prime}\right) .
$$

All parties know the value of the fixed bargaining cost $c$ when they start playing the game. By introducing the bargaining cost, we assume that the payments of parties which choose a government by negotiations decrease when the parties continue to bargain: the credibility and the goodwill of a future government in the eyes of the public decrease if an agreement on creating a government cannot be reached easily. On the other hand, condition (8) says that the bargaining cost is still small enough. This means that, if a party prefers one government to another, it will prefer that this 'better' government is chosen, even in the last period of the bargaining, rather than that the 'worse' one is chosen immediately, that is, in period 1.

GAME $A^{\prime}$ is similar to Game A, except that we do NOT assume condition (8), and we generalize condition (7). Instead of one constant bargaining cost $c>0$, we assume a sequence of possibly different bargaining costs $\left(c_{t}\right)_{t=1}^{|C G|}$, where $c_{t}$ means the bargaining cost in period $t$. Since we do not assume condition (8), the values of the bargaining costs may be quite large. In explanation, we can say that, for instance, the cost in period $t>1$ is high if time between rejecting an offer in period $t-1$ and submitting a new one in period $t$ is (very) long. Formally, we have for all $i \in N^{C G}$, for all $g \in C G$ and for all $T \in\{1, \ldots,|C G|\}$

$$
U_{i}(g, T)=U_{i}(g)-\sum_{t=1}^{T} c_{t}
$$

where $c_{t}$ is the bargaining cost in period $t$. We assume $c_{1}=0$, and $c_{t}>0$ for each $1<t \leq$ $|C G|$.

GAME $B$ is like game A except that in the bargaining procedure for game B ALL parties belonging to at least one government from $C G$ (not necessarily belonging to the proposed government) have to either accept or reject the government proposed. Moreover, a party may propose a government from $C G$ to which the party does NOT belong.

$G A M E B^{\prime}$ is like Game $\mathrm{B}$, but again with a sequence of bargaining costs $\left(c_{t}\right)_{t=1}^{|C G|}$ as in Game $\mathrm{A}^{\prime}$. We do not assume condition (8) and replace condition (7) by condition (9).

GAME C is similar to game A, but now the 'strongest' party in $\overline{N^{C G}}$ (that is, party $n_{1} \in \overline{N^{C G}}$ ) is the only one party submitting offers; $n_{1}$ may propose governments it does not belong to.

GAME $C^{\prime}$ has the same rules as Game C, but again with possibly different costs over time instead of a constant cost $c$. So, in Game $C^{\prime}$ we do not assume condition (8), and we replace condition (7) by condition (9).

We like to make some remarks concerning the games defined. First of all, each game defined is a game with perfect and complete information, since the parties know each other's preferences 
and they neither use a secret procedure nor bargain simultaneously. Since we have perfect information, each information set in the extensive form of the game has only one element. A strategy of a party participating in the negotiations is a description of its behavior in each situation in which it has to act. In each information set of a given party, it has either to propose one government from among all governments from $C G$ which have not been proposed before (and for Games A and A', to which this party belongs), or to choose between 'yes' and 'no'.

Let us try to compare the games defined in this section. In all games considered, we invite for negotiations all parties which are 'personally' interested in the result of such negotiations, that is, parties that might be responsible for a future government. Since one government from $C G$ has to be chosen, only parties involved in at least one government from $C G$ play our games. In Games $\mathrm{A}$ and $\mathrm{A}^{\prime}$, parties are involved in bargaining over a given government only if the party belongs to this government. Examples show that a party may be better off when it is not the first proposer; see Remark 4.1. In Games B and $\mathrm{B}^{\prime}$, we give a chance to all parties involved in at least one government from $C G$ to have influence on the result of the negotiations. As we will see in Remark 4.2, it may happen that a party involved in a chosen government is better off if some parties which do not belong to this government also participated in the negotiations. Finally, we analyze Games $C$ and $C^{\prime}$ in which the 'strongest' party is the only one which may submit an offer. Games $C$ and $C^{\prime}$ seem to be closer to reality. In real politics, most frequently it is the greatest party which tries to form a government by making offers to other parties. Nevertheless, it appears that sometimes it will be better for a party if it is another party that makes the offers; for an example, see Remark 4.3. The difference between games denoted by the same letter (for instance, between $\mathrm{A}$ and $\mathrm{A}^{\prime}$ ) concerns only the bargaining costs. In Games $\mathrm{A}, \mathrm{B}$, and $\mathrm{C}$ we assume the constant bargaining cost $c>0$ to satisfy condition (8). In Games $\mathrm{A}^{\prime}, \mathrm{B}^{\prime}$, and $\mathrm{C}^{\prime}$ we assume a sequence of bargaining costs $\left(c_{t}\right)_{t=1}^{|C G|}, c_{1}=0, c_{t}>0$ for $1<t \leq|C G|$, which may be arbitrary large.

The question arises whether our bargaining games have subgame perfect equilibria, and, if so, what they look like and to which governments they lead. The notion of subgame perfect equilibrium is a well-known refinement of the notion of Nash equilibrium, introduced by Reinhard Selten (1975). By definition, a subgame perfect equilibrium is a Nash equilibrium in each subgame of the game. In order to find subgame perfect equilibria, we can use backward induction. Starting from the end points of the extensive form game and going backwards to its beginning, we choose the best moves of the players in each information set.

As we have already noted, our negotiations will result in one government being chosen. As the notion of subgame perfect equilibrium is a refinement of the notion of Nash equilibrium, we would suggest the following advice to negotiating parties:

If there is (at least one) subgame perfect equilibrium for the bargaining game defined, use (one of) your subgame perfect equilibrium strategies.

One can prove the following proposition:

Proposition 3.1 For all the bargaining games described, there is (at least one) subgame perfect equilibrium.

Proof Each of the games A, A', B, B', C, and $\mathrm{C}^{\prime}$ is a finite extensive game with perfect information, and hence, according to (Mas-Colell et al. 1995, Proposition 9.B.2) and (Osborne and Rubinstein 1994, Proposition 99.2), it has a (pure) subgame perfect equilibrium.

Below, we indicate some 'safe' games for the 'strongest' party, that is games giving the best result for party $n_{1}$ if all parties play their subgame perfect equilibrium strategies. 
Proposition 3.2 Let $B G$ be the set of all games considered, that is, $B G=\left\{A, A^{\prime}, B, B^{\prime}, C\right.$, $\left.C^{\prime}\right\}$. Moreover, let $g^{*}=\left(S^{*}, p^{*}\right)$ be the unique best government from $C G$ for $n_{1}$, where $n_{1}$ is the first party submitting an offer in all games from $B G$. Let $B G^{*}$ be the set of all bargaining games from $B G$ in which all subgame perfect equilibria lead to the result $\left(g^{*}, 1\right)$. Let us consider the following conditions:

$$
\begin{gathered}
\forall i \in S^{*} \backslash\left\{n_{1}\right\} \forall(S, p) \in C G \backslash\left\{g^{*}\right\}[i \notin S] \\
\forall i \in S^{*} \forall g \in C G \backslash\left\{g^{*}\right\}\left[U_{i}\left(g^{*}\right)>U_{i}(g)\right] \\
\forall i \in S^{*} \forall g \in C G \backslash\left\{g^{*}\right\}\left[c_{2}>U_{i}(g)-U_{i}\left(g^{*}\right)\right] \\
\forall i \in N^{C G} \forall g \in C G \backslash\left\{g^{*}\right\}\left[c_{2}>U_{i}(g)-U_{i}\left(g^{*}\right)\right],
\end{gathered}
$$

where $c_{2}>0$ is the bargaining cost in period 2. It is true that:

(a) $\left(n_{1} \in S^{*} \wedge(10)\right) \Longrightarrow A \in B G^{*}$

(b) (11) $\Longrightarrow C \in B G^{*}$

(c) $\left(n_{1} \in S^{*} \wedge(11)\right) \Longrightarrow\left(A \in B G^{*} \wedge C \in B G^{*}\right)$

(d) $(12) \Longrightarrow C^{\prime} \in B G^{*}$

(e) $\left(n_{1} \in S^{*} \wedge(12)\right) \Longrightarrow\left(A^{\prime} \in B G^{*} \wedge C^{\prime} \in B G^{*}\right)$

(f) $(13) \Longrightarrow\left(B^{\prime} \in B G^{*} \wedge C^{\prime} \in B G^{*}\right)$

(g) $\left(n_{1} \in S^{*} \wedge(13)\right) \Longrightarrow\left(A^{\prime} \in B G^{*} \wedge B^{\prime} \in B G^{*} \wedge C^{\prime} \in B G^{*}\right)$.

Proof (a) Suppose that $n_{1} \in S^{*}$ and condition (10) is satisfied. Then, $n_{1}$ is the only party from $S^{*}$ which may belong to more than one government from $C G$. Hence, when playing Game A, if $n_{1}$ proposes $g^{*}$ in period 1, all remaining members of $S^{*}$ have to say 'yes', because they have nothing more to propose. This means that $\mathrm{A} \in B G^{*}$.

(b), (c) Let us assume that condition (11) is satisfied. Hence, when playing Game C, if $n_{1}$ proposes $g^{*}$ in period 1, then all parties which have to respond, that is, all members of $S^{*} \backslash\left\{n_{1}\right\}$, will say 'yes' due to (11), what means that $\mathrm{C} \in B G^{*}$. If additionally, $n_{1} \in S^{*}$, then, when playing Game A, $n_{1}$ may propose $g^{*}$ in period 1, and due to (11) all remaining parties from $S^{*}$ will accept it. Hence, $\mathrm{A} \in B G^{*}$.

(d), (e) Now we assume condition (12) to be satisfied. This means that if $n_{1}$ proposes $g^{*}$ in period 1, all responding parties will say 'yes'. This happens because, by virtue of (12), for each party from $S^{*}$, the payment for the result $\left(g^{*}, 1\right)$ is greater than the payment for the result $(g, 2)$ for any other government $g \in C G$. Hence, $C^{\prime} \in B G^{*}$. If additionally, $n_{1} \in S^{*}$, then $n_{1}$ may propose $g^{*}$ also in Game $\mathrm{A}^{\prime}$, and hence, $\mathrm{A}^{\prime} \in B G^{*}$.

(f), (g) Let us suppose that condition (13) is satisfied. This means that all parties belonging to at least one government from $C G$ find the result $\left(g^{*}, 1\right)$ better than the result $(g, 2)$ for any other government $g$ from $C G$. Since in $\mathrm{B}^{\prime}$ and in $\mathrm{C}^{\prime}, n_{1}$ may propose $g *$ in period 1 , $\mathrm{B}^{\prime} \in B G^{*}$ and $\mathrm{C}^{\prime} \in B G^{*}$. If additionally, $n_{1} \in S^{*}$, then also $\mathrm{A}^{\prime} \in B G^{*}$.

Conclusion 3.1 There is always a bargaining game $G \in B G$ in which all subgame perfect equilibria lead to the result which is best for party $n_{1}$.

Proof Each Game $\mathrm{C}^{\prime}$ with $c_{2}$ satisfying (12) belongs to $B G^{*}$ by virtue of implication (d) in Proposition 3.2. 


\subsection{Comparison with Related Literature}

Contrary to many other models, our model considers both office seeking motivations and policy preferences, by treating the government coalition in the same way as the policies. The policies in our model may be multidimensional and the number of parties is arbitrary.

David Austen-Smith and Jeffrey Banks (1988) conceive of portfolios as benefits and a party can be induced to join a government and compromise over the policy choice by offering it some portfolios. The model presented in this paper has only three parties and a onedimensional policy space. The party with the largest number of seats proposes a coalition, a policy, and a portfolio distribution, and if the parties which accept the proposal form a winning coalition, the government forms. If not enough parties accept the proposal in order to form a winning coalition, then the party with the second highest number of seats proposes a coalition, a policy and a portfolio distribution, and the members of the proposed coalition respond to the proposal. If neither the second nor the third government forms, a certain government is formed which decides 'equitably' about the policy and the portfolio distribution. There are several differences between the model of Austen-Smith and Banks and our model, and some advancements of the latter, like an arbitrary number of parties and multidimensional policies. Also, in our present model the portfolio distribution may be incorporated just as a policy sub-issue. Moreover, while Austen-Smith and Banks present one bargaining procedure, in which a majority of the proposed coalition must accept the proposal, we define several bargaining games, which differ from each other with respect to the bargaining procedure and/or bargaining costs. We compare the games and search for the one which is best for the strongest party. In our model, either all parties forming a proposed coalition (like in Games A and C) or all parties involved in the bargaining (like in Game B) must approve the proposal. The bargaining is not simultaneous but sequential: the parties respond according to the given order. Moreover, either a rejecting party (like in Games A and B) or always the strongest party (like in Game C) submits a new proposal. In the model of Austen-Smith and Banks, in case no government is agreed on, a certain government called 'caretaker government' is implemented. In our model, in case no government is agreed on, the last proposed government forms. Hence, we do not involve any 'outside government', but we choose only a government from among all stable governments (or from all feasible governments if there is no stable one).

The model presented by David Austen-Smith and Jeffrey Banks (1990) pays much attention to the portfolio allocation and consists of two steps: a portfolio allocation in the first stage and in the second stage the parties comprising the government interact to determine a policy outcome, where in general such interaction will be a function of the portfolio allocation. In our model of coalition formation we may include the portfolio allocation as a policy sub-issue, which then together with the other policy sub-issues determines a policy, which in its turn together with a feasible coalition may form a government with a certain utility to each party. David Austen-Smith and Jeffrey Banks (1990) focus on a stable portfolio allocation and consider several notions of stability. Their paper is therefore more related to Rusinowska et al. (2005), where we investigate the notion of stable government. Similar to Austen-Smith and Banks (1990), we consider alternative definitions of 'stability' and relate them to the concept of the core.

Daniel Diermeier and Antonio Merlo (2000) present a two-period model of government formation and termination, in which both majoritarian (i.e., minimal winning and surplus) governments and minority governments may form. The model accounts for the relative instability of minority governments and for the cabinet terminations due to replacement or early elections. In each period two shocks are realized: a shock determining the policy that would 
be implemented if no government forms, and a shock determining the electoral prospects of all parties if parliament were dissolved and an election held. After observing the shocks, parties negotiate over policy and distributive benefits. If no government is in power, a party selected by the head of the state and called the formateur tries to form a new government, while if a government is in power, parties negotiate over whether to preserve the current government or to terminate it. If a government is terminated, parties decide whether to replace it immediately by a new government or to call an early election before the formation of a new government. In a similar way as in our model, subgame perfect equilibria of the game are investigated. However, in the paper it is assumed that there are three parties and a two-dimensional policy space. As mentioned before, the policies in our model may be multidimensional, and the benefits may be incorporated just as a policy sub-issue. Also the number of parties is arbitrary in our model. Moreover, we do not focus on one bargaining procedure, but we present several games and compare them.

Massimo Morelli (1999) proposes a model of majoritarian bargaining in which players demand a compensation for their participation in a coalition and in which the order of play is endogenous, in that the head of state chooses the first mover, and the latter chooses the order of response. Each party's strategy at each bargaining round contains a demand that may specify a policy proposal and the amount of private benefits (ministerial and nonministerial payoffs) a party would want if selected in a majority coalition. The subgame perfect equilibrium payoff distribution of the bargaining game introduced there is proportional to the exante distribution of bargaining power and approximately proportional to the distribution of seats in the winning coalition. However, the model in Morelli (1999) has a unidimensional policy space. Massimo Morelli remarks in the conclusion that 'When this model is extended to multidimensional policy spaces, I expect to obtain an explanation of why parties outside a government coalition often receive positive payoffs'. Our results further on for the given example seem to confirm this expectation. Moreover, while in Morelli (1999) one bargaining procedure is considered, in our paper we define and compare several bargaining procedures. Furthermore, while Morelli assumes a discount factor which is constant for all rounds of the bargain, in our paper, for some types of the games, we assume a sequence of bargaining costs, that is, the bargaining costs may be different from each other in each round.

In the literature, one can find several works in which bargaining models of government formation are estimated. Antonio Merlo (1997) structurally estimates a multilateral stochastic model of sequential bargaining and he focuses on the timing and the terms of government agreements. Policy experiments to evaluate the effects of changes in the bargaining procedure are conducted. The author shows that the model fits well postwar Italian data on the duration and negotiations over the formation of new governments and government durations. A sequence of 47 Italian governments over the period 1948-1994 has been analyzed.

Daniel Diermeier and Antonio Merlo (2004) present an empirical investigation of two coalitional bargaining procedures: a procedure proposed by Austen-Smith and Banks (1988) and a procedure proposed by Baron and Ferejohn (1989). Diermeier and Merlo conclude that there is little empirical support for the coalitional bargaining procedure proposed in AustenSmith and Banks (1988), which postulates that parties are selected to make government proposals in order of their seat shares. Next they conclude that the coalitional bargaining procedure proposed in Baron and Ferejohn (1989), which postulates that the probability parties are selected to make government proposals is proportional to their seat shares, can be justified on empirical grounds and captures important features of the data.

Daniel Diermeier et al. (2003) estimate a bargaining model of government formation that builds on their previous work presented in Diermeier and Merlo (2000) and Merlo (1997). They conduct constitutional experiments to investigate the impact of specific institutional 
features of parliamentary democracies on the government formation process. In the paper, 255 governments in nine West European countries over the period 1947-1999 are considered.

In our future research we would like to follow the works, in which the government formation models have been estimated, and to conduct empirical research on our model. Since our model, on the one hand differs from the pre-existing models on government formation, and on the other hand has its advancements, experiments on this model and the bargaining procedures may give interesting and meaningful results.

\section{The Example}

In order to illustrate the notions introduced, we will construct a relatively simple theoretical example based on the Polish government. In our example, we assume the real structure of the Polish government after the 2001 elections, but any additional assumptions (concerning, for instance, policy issues, budget, the preferences of each party) will be purely theoretical and simplified.

Let us suppose that the Polish government has to decide on two independent issues: education+medical services, and foreign policy. Both issues consist of some dependent subissues. We assume that there is one fixed budget (let us say, 100) for both education and medical services. This means that if a government assigns a larger budget for education, it has to spend less on medical services. Moreover, we assume that a decision about introducing a certain reform of the educational system has to be made. Introducing such a reform also implies a larger budget for education (let us say, at least $1 / 4$ of this budget, that is, 25 has to be spent on education if the reform is planned). In the matter of foreign policy, we assume that the government has to decide whether Poland will attempt to enter the European Union or not, and depending on this decision, it has to choose a kind of foreign policy. If Poland wants to enter the European Union, the government has to choose one foreign policy from among $a, b$, and $c$, and otherwise, it must choose from the set $\{d, e, f\}$.

So, more formally, we assume the following two issues $(M=2)$ and sub-issues:

Issue 1: education and medical services:

sub-issue 1(1) with policy subspace $B_{1(1)}=\{y e s, n o\}$ : introducing a reform of the educational system;

sub-issue 1(2) with policy subspace $B_{1(2)}=[0,100]$ : expenditure for education; sub-issue 1(3) with policy subspace $B_{1(3)}=[0,100]$ : expenditure for medical services.

Issue 2: foreign policy:

sub-issue 2(1) with policy subspace $B_{2(1)}=\{y e s$, no $\}$ : entering the European Union; sub-issue 2(2) with policy subspace $B_{2(2)}=\{a, b, c, d, e, f\}$ : choosing a foreign policy.

Given the description above, the policy space $B$ is by definition $B_{1} \times B_{2}$ with

$$
\begin{aligned}
B_{1}= & \left\{\left(\text { yes }, p_{1(2)}, p_{1(3)}\right): p_{1(2)}+p_{1(3)}=100 \wedge p_{1(2)} \geq 25 \wedge p_{1(3)} \geq 0\right\} \cup \\
& \left\{\left(\text { no }, p_{1(2)}, p_{1(3)}\right): p_{1(2)}+p_{1(3)}=100 \wedge p_{1(2)} \geq 0 \wedge p_{1(3)} \geq 0\right\} \\
B_{2}= & \{(\text { yes }, a),(\text { yes }, b),(\text { yes }, c),(\text { no }, d),(\text { no }, e),(\text { no }, f)\}
\end{aligned}
$$

After the last parliamentary elections in Poland, which were held in September 2001, the Lower House of the Polish Parliament consisted of the following parties: 
1. SLD + UP: Coalition of SLD (Alliance of the Democratic Left) and UP (Labour Union)-216 seats,

2. PO: Civil Platform-65 seats,

3. SAM: Self-Defence-53 seats,

4. PiS: Law and Justice-44 seats,

5. PSL: Polish Peasant Party-42 seats,

6. LPR: Polish Family Alliance-38 seats,

7. $M N$ : German Minority-2 seats.

For our example, we have $n=7$ and

$$
N=\{S L D+U P, P O, S A M, P i S, P S L, L P R, M N\} .
$$

The total number of seats in the Lower House of the Polish Parliament is 460. We assume absolute majority, hence $q=231$. The weight $w_{i}$ of each party $i \in N$ is the number of seats assigned to the party after the election.

We will determine all feasible governments for our leading example. Let us start with feasible coalitions. Although there are many majority coalitions in our example, we assume that only three of them are feasible:

$$
F C=\{S L D-P S L, S L D-P O, S L D-P i S\}
$$

Table 1 shows the values assumed for these feasible coalitions. We restrict our analysis to the parties forming the feasible coalitions.

Tables 2 and 3 present the values to a party from $F C$ of policies on issues 1 and 2 , respectively. In Table 2 , we included only policies on issue 1 that have a non-negative value for at least one party.

From Tables 2 and 3, we can construct $6 \times 6=36$ policies. Let

$$
U=\left(U_{S L D}, U_{P O}, U_{P i S}, U_{P S L}\right) .
$$

Table 1 Values $U_{i}(S)$ of feasible coalitions $S$

Table 2 Values $U_{i}\left(p_{1}\right)$ of some policies $p_{1}$ on issue 1 'education and medical services'

\begin{tabular}{llccc}
\hline$i$ & SLD+UP (SLD) & PO & PiS & PSL \\
\hline$S$ & & & & \\
$S L D-P S L$ & 1 & 0 & 0 & 1 \\
$S L D-P O$ & $\frac{2}{3}$ & $\frac{1}{3}$ & 0 & $\frac{1}{3}$ \\
$S L D-P i S$ & 0 & -3 & $\frac{1}{3}$ & -3 \\
\hline
\end{tabular}

\begin{tabular}{lllll}
\hline$i$ & SLD + UP & PO & PiS & PSL \\
\hline$p_{1}=\left(p_{1(1)}, p_{1(2)}, 100-p_{1(2)}\right)$ & & & & \\
$p_{1(1)}=y e s, p_{1(2)} \in[30,40)$ & -3 & $\frac{1}{3}$ & $\frac{1}{3}$ & -3 \\
$p_{1(1)}=$ yes, $p_{1(2)} \in[40,50)$ & $\frac{1}{3}$ & 1 & 1 & -3 \\
$p_{1(1)}=$ yes, $p_{1(2)} \in[50,60)$ & $\frac{1}{3}$ & 1 & 1 & $\frac{2}{3}$ \\
$p_{1(1)}=$ yes, $p_{1(2)}=60$ & $\frac{2}{3}$ & 1 & 1 & $\frac{2}{3}$ \\
$p_{1(1)}=$ no, $p_{1(2)} \in[40,50)$ & 0 & -3 & -3 & -3 \\
$p_{1(1)}=$ no, $p_{1(2)}=50$ & 1 & $\frac{2}{3}$ & -3 & 0 \\
\hline
\end{tabular}


Table 3 Values $U_{i}\left(p_{2}\right)$ of policies $p_{2}$ on issue 2 'foreign policy'

\begin{tabular}{lllll}
\hline$i$ & SLD +UP & PO & PiS & PSL \\
\hline$p_{2}$ & & & & \\
$($ yes,$a)$ & -3 & 1 & 1 & 0 \\
$($ yes,$b)$ & $\frac{1}{3}$ & 1 & $\frac{1}{3}$ & $\frac{1}{3}$ \\
$($ yes,$c)$ & 1 & $\frac{1}{3}$ & 1 & -3 \\
$($ no, $d)$ & -3 & -3 & -3 & -3 \\
$($ no, $e)$ & -3 & -3 & -3 & $\frac{1}{3}$ \\
$($ no,$f)$ & -3 & -3 & -3 & -3
\end{tabular}

Let us write down the values of several policies, for instance:

$$
p^{\prime}=((n o, 50,50),(\text { yes }, b)) \text { and } p^{\prime \prime}=\left(\left(\text { yes },[40,50), p_{1(3)}\right),(\text { yes }, b)\right)
$$

By virtue of Eq. 2 and Tables 2 and 3, we have

$$
U\left(p^{\prime}\right)=\left(\frac{4}{3}, \frac{5}{3},-\frac{8}{3}, \frac{1}{3}\right) \quad \text { and } \quad U\left(p^{\prime \prime}\right)=\left(\frac{2}{3}, 2, \frac{4}{3},-\frac{8}{3}\right) .
$$

Finally, again using (2), we can calculate the values of the governments. For instance, the values of $g^{\prime}=\left(S L D-P O, p^{\prime}\right)$ and $g^{\prime \prime}=\left(S L D-P S L, p^{\prime \prime}\right)$ are the following:

$$
U\left(g^{\prime}\right)=\left(2,2,-\frac{8}{3}, \frac{2}{3}\right) \text { and } U\left(g^{\prime \prime}\right)=\left(\frac{5}{3}, 2, \frac{4}{3},-\frac{5}{3}\right)
$$

Note that, for example, for $P O, g^{\prime}$ and $g^{\prime \prime}$ have the same values, which means that $P O$ is indifferent regarding the choice between $\left(S L D-P O, p^{\prime}\right)$ and $\left(S L D-P S L, p^{\prime \prime}\right): S L D-P O$ has the value $\frac{1}{3}$ for $P O$ and $p^{\prime}$ has the value $\frac{5}{3}$ for $P O$, while $S L D-P S L$ has the value 0 for $P O$ and $p^{\prime \prime}$ has the value 2 for $P O$.

Next, we will write down all feasible governments. To start with, Table 4 presents all feasible policies and their values.

Table 4 All feasible policies $p$ for feasible coalitions $S U=\left(U_{S L D}, U_{P O}, U_{P i S}, U_{P S L}\right)$

\begin{tabular}{lll}
\hline Feasible policy $p$ for $S$ & Feasible coalition $S$ & $U(p)$ \\
\hline$p^{(1)}=\left(\left(\right.\right.$ yes $\left.,[40,50), p_{1(3)}\right),($ yes,$\left.b)\right)$ & SLD-PO, SLD-PiS & $\left(\frac{2}{3}, 2, \frac{4}{3},-\frac{8}{3}\right)$ \\
$p^{(2)}=\left(\left(\right.\right.$ yes $\left.,[40,50), p_{1(3)}\right),($ yes,$\left.c)\right)$ & SLD-PO, SLD-PiS & $\left(\frac{4}{3}, \frac{4}{3}, 2,-6\right)$ \\
$p^{(3)}=\left(\left(\right.\right.$ yes $\left.,[50,60), p_{1(3)}\right),($ yes,$\left.b)\right)$ & SLD-PO, SLD-PiS & $\left(\frac{2}{3}, 2, \frac{4}{3}, 1\right)$ \\
& SLD-PSL & \\
$p^{(4)}=\left(\left(\right.\right.$ yes $\left.,[50,60), p_{1(3)}\right),($ yes,$\left.c)\right)$ & SLD-PO, SLD-PiS & $\left(\frac{4}{3}, \frac{4}{3}, 2,-\frac{7}{3}\right)$ \\
$p^{(5)}=(($ yes $, 60,40),($ yes,$b))$ & SLD-PO, SLD-PiS & $\left(1,2, \frac{4}{3}, 1\right)$ \\
$p^{(6)}=(($ yes $, 60,40),($ yes,$c))$ & SLD-PSL & \\
$p^{(7)}=(($ no $, 50,50),($ yes,$b))$ & SLD-PO, SLD-PiS & $\left(\frac{5}{3}, \frac{4}{3}, 2,-\frac{7}{3}\right)$ \\
$p^{(8)}=(($ no $, 50,50),($ yes,$c))$ & SLD-PO, SLD-PSL & $\left(\frac{4}{3}, \frac{5}{3},-\frac{8}{3}, \frac{1}{3}\right)$ \\
\end{tabular}


Table 5 All feasible governments $U=\left(U_{S L D}, U_{P O}, U_{P i S}, U_{P S L}\right)$

\begin{tabular}{|c|c|c|c|}
\hline$(S, p)$ & $U(S)$ & $U(p)$ & $U(S, p)$ \\
\hline$\left(S L D-P O, p^{(1)}\right)$ & $\left(\frac{2}{3}, \frac{1}{3}, 0, \frac{1}{3}\right)$ & $\left(\frac{2}{3}, 2, \frac{4}{3},-\frac{8}{3}\right)$ & $\left(\frac{4}{3}, \frac{7}{3}, \frac{4}{3},-\frac{7}{3}\right)$ \\
\hline$\left(S L D-P i S, p^{(1)}\right)$ & $\left(0,-3, \frac{1}{3},-3\right)$ & $\left(\frac{2}{3}, 2, \frac{4}{3},-\frac{8}{3}\right)$ & $\left(\frac{2}{3},-1, \frac{5}{3},-\frac{17}{3}\right)$ \\
\hline$\left(S L D-P O, p^{(2)}\right)$ & $\left(\frac{2}{3}, \frac{1}{3}, 0, \frac{1}{3}\right)$ & $\left(\frac{4}{3}, \frac{4}{3}, 2,-6\right)^{\prime}$ & $\left(2, \frac{5}{3}, 2,-\frac{17}{3}\right)$ \\
\hline$\left(S L D-P i S, p^{(2)}\right)$ & $\left(0,-3, \frac{1}{3},-3\right)$ & $\left(\frac{4}{3}, \frac{4}{3}, 2,-6\right)$ & $\left(\frac{4}{3},-\frac{5}{3}, \frac{7}{3},-9\right)$ \\
\hline$\left(S L D-P O, p^{(3)}\right)$ & $\left(\frac{2}{3}, \frac{1}{3}, 0, \frac{1}{3}\right)$ & $\left(\frac{2}{3}, 2, \frac{4}{3}, 1\right)$ & $\left(\frac{4}{3}, \frac{7}{3}, \frac{4}{3}, \frac{4}{3}\right)$ \\
\hline$\left(S L D-P i S, p^{(3)}\right)$ & $\left(0,-3, \frac{1}{3},-3\right)$ & $\left(\frac{2}{3}, 2, \frac{4}{3}, 1\right)$ & $\left(\frac{2}{3},-1, \frac{5}{3},-2\right)$ \\
\hline$\left(S L D-P S L, p^{(3)}\right)$ & $(1,0,0,1)$ & $\left(\frac{2}{3}, 2, \frac{4}{3}, 1\right)$ & $\left(\frac{5}{3}, 2, \frac{4}{3}, 2\right)$ \\
\hline$\left(S L D-P O, p^{(4)}\right)$ & $\left(\frac{2}{3}, \frac{1}{3}, 0, \frac{1}{3}\right)$ & $\left(\frac{4}{3}, \frac{4}{3}, 2,-\frac{7}{3}\right)$ & $\left(2, \frac{5}{3}, 2,-2\right)$ \\
\hline$\left(S L D-P i S, p^{(4)}\right)$ & $\left(0,-3, \frac{1}{3},-3\right)$ & $\left(\frac{4}{3}, \frac{4}{3}, 2,-\frac{7}{3}\right)$ & $\left(\frac{4}{3},-\frac{5}{3}, \frac{7}{3},-\frac{16}{3}\right)$ \\
\hline$\left(S L D-P O, p^{(5)}\right)$ & $\left(\frac{2}{3}, \frac{1}{3}, 0, \frac{1}{3}\right)$ & $\left(1,2, \frac{4}{3}, 1\right)$ & $\left(\frac{5}{3}, \frac{7}{3}, \frac{4}{3}, \frac{4}{3}\right)$ \\
\hline$\left(S L D-P i S, p^{(5)}\right)$ & $\left(0,-3, \frac{1}{3},-3\right)$ & $\left(1,2, \frac{4}{3}, 1\right)$ & $\left(1,-1, \frac{5}{3},-2\right)$ \\
\hline$\left(S L D-P S L, p^{(5)}\right)$ & $(1,0,0,1)$ & $\left(1,2, \frac{4}{3}, 1\right)$ & $\left(2,2, \frac{4}{3}, 2\right)$ \\
\hline$\left(S L D-P O, p^{(6)}\right)$ & $\left(\frac{2}{3}, \frac{1}{3}, 0, \frac{1}{3}\right)$ & $\left(\frac{5}{3}, \frac{4}{3}, 2,-\frac{7}{3}\right)$ & $\left(\frac{7}{3}, \frac{5}{3}, 2,-2\right)$ \\
\hline$\left(S L D-P i S, p^{(6)}\right)$ & $\left(0,-3, \frac{1}{3},-3\right)$ & $\left(\frac{5}{3}, \frac{4}{3}, 2,-\frac{7}{3}\right)$ & $\left(\frac{5}{3},-\frac{5}{3}, \frac{7}{3},-\frac{16}{3}\right)$ \\
\hline$\left(S L D-P O, p^{(7)}\right)$ & $\left(\frac{2}{3}, \frac{1}{3}, 0, \frac{1}{3}\right)$ & $\left(\frac{4}{3}, \frac{5}{3},-\frac{8}{3}, \frac{1}{3}\right)$ & $\left(2,2,-\frac{8}{3}, \frac{2}{3}\right)$ \\
\hline$\left(S L D-P S L, p^{(7)}\right)$ & $(1,0,0,1)$ & $\left(\frac{4}{3}, \frac{5}{3},-\frac{8}{3}, \frac{1}{3}\right)$ & $\left(\frac{7}{3}, \frac{5}{3},-\frac{8}{3}, \frac{4}{3}\right)$ \\
\hline$\left(S L D-P O, p^{(8)}\right)$ & $\left(\frac{2}{3}, \frac{1}{3}, 0, \frac{1}{3}\right)$ & $(2,1,-2,-3)$ & $\left(\frac{8}{3}, \frac{4}{3},-2,-\frac{8}{3}\right)$ \\
\hline
\end{tabular}

As we can see from Table 4, there is an infinite number of feasible policies available for the composition of feasible governments (we denoted them as $p^{(1)}-p^{(8)}$ ), there are three feasible coalitions, and finally, there is an infinite number of feasible governments. Nevertheless, each two policies belonging to the same $p^{(k)}, k=1, \ldots, 8$, are equivalent. Hence, we consider only a finite number of policies, and a finite number of governments. Note that the policies shown in Table 4 are feasible for several (majority) coalitions.

Table 5 shows all feasible governments for our example. Let us check now which of the feasible governments presented in Table 5, if any, are stable. It appears that only three feasible governments, that is, $\left(S L D-P S L, p^{(5)}\right),\left(S L D-P S L, p^{(7)}\right)$, and $\left(S L D-P O, p^{(8)}\right)$ are dominated by no feasible government. Hence, we get three stable governments:

$$
S G=\left\{g^{(1)}, g^{(2)}, g^{(3)}\right\}, \text { where }
$$

$g^{(1)}=\left(S L D-P S L, p^{(5)}\right)$ with $p^{(5)}=(($ yes $, 60,40),($ yes,$b))$,

$g^{(2)}=\left(S L D-P S L, p^{(7)}\right)$ with $p^{(7)}=(($ no, 50, 50), $($ yes,$b))$,

$g^{(3)}=\left(S L D-P O, p^{(8)}\right)$, with $p^{(8)}=(($ no, 50, 50),$($ yes,$c))$

Table 6 presents the stable governments and their values. Since $P i S$ is not involved in further negotiations, we restrict our analysis to parties $S L D, P O$ and $P S L$, and now we assume that $U=\left(U_{S L D}, U_{P O}, U_{P S L}\right)$.

Our example is purely theoretical, as an analysis of Table 6 shows. We get, for instance, that governments $g^{(1)}$ and $g^{(2)}$, in which $S L D$ creates a coalition with $P S L$, are more preferred 
Table 6 Stable governments $U=\left(U_{S L D}, U_{P O}, U_{P S L}\right)$

\begin{tabular}{llll}
\hline$g=(S, p)$ & $U(S)$ & $U(p)$ & $U(g)$ \\
\hline$g^{(1)}=\left(S L D-P S L, p^{(5)}\right)$ & $(1,0,1)$ & $(1,2,1)$ & $(2,2,2)$ \\
$g^{(2)}=\left(S L D-P S L, p^{(7)}\right)$ & $(1,0,1)$ & $\left(\frac{4}{3}, \frac{5}{3}, \frac{1}{3}\right)$ & $\left(\frac{7}{3}, \frac{5}{3}, \frac{4}{3}\right)$ \\
$g^{(3)}=\left(S L D-P O, p^{(8)}\right)$ & $\left(\frac{2}{3}, \frac{1}{3}, \frac{1}{3}\right)$ & $(2,1,-3)$ & $\left(\frac{8}{3}, \frac{4}{3},-\frac{8}{3}\right)$ \\
\hline
\end{tabular}

by $P O$ than government $g^{(3)}$, in which $S L D$ forms a coalition with $P O$. Although $P O$ prefers coalition $S L D-P O$ to coalition $S L D-P S L$, it finds policy $p^{(8)}$ much less attractive than policies $p^{(5)}$ and $p^{(7)}$, and hence, finally, $P O$ prefers governments with $S L D-P S L$ (as a governing coalition) to a government with $S L D-P O$. One may say that in this example, $P O$ prefers moving to the opposition instead of belonging to the government. Such a situation, although it can be explained, does not seem to be so realistic. However, our main aim when constructing this example was not to present the actual preferences of the Polish parties and the real political situation in Poland, but rather to use the composition of the Polish Parliament in order to show how our definitions (in particular, the negotiations) can be applied and how they work.

Let us apply now the bargaining procedures introduced in the preceding section to our example with three stable governments: $C G=S G=\left\{g^{(1)}, g^{(2)}, g^{(3)}\right\}, N^{C G}=\{S L D, P O$, $P S L\},|C G|=3, n^{C G}=3$.

In the further considerations, no matter which order is assumed, $\left(f_{1}, f_{2}, f_{3}\right)$ will denote a subgame perfect equilibrium, where $f_{1}$ denotes the strategy of $S L D, f_{2}$ the strategy of $P O$ and $f_{3}$ the strategy of $P S L$.

\subsection{Games A and $\mathrm{A}^{\prime}$}

Since in our example all coalitions belonging to stable governments are only two-party coalitions, the ordered lists of parties having the same starting party give precisely the same extensive form games $\mathrm{A}$ and $\mathrm{A}^{\prime}$. Hence, $\overline{N^{S G}}=(S L D, P O, P S L)$ and $\overline{N^{S G}}=$ ( $S L D, P S L, P O)$ create the same games. Similarly, the ordered lists $\overline{N^{S G}}=(P O, S L D$, $P S L)$ and $\overline{N^{S G}}=(P O, P S L, S L D)$ give the same extensive form games, and finally, $\overline{N^{S G}}=(P S L, S L D, P O)$ and $\overline{N^{S G}}=(P S L, P O, S L D)$ form the same bargaining games.

Let us consider Games A and $\mathrm{A}^{\prime}$, where $\overline{N^{S G}}=(S L D, P O, P S L)$ or $\overline{N^{S G}}=(S L D$, $P S L, P O)$. This means that $S L D$ starts the bargaining, proposing one of the three governments in period 1 . If it proposes $g^{(3)}$, then the game is over with the result $\left(g^{(3)}, 1\right)$, because $P O$ has no other offer to submit ( $P O$ is only a member of $\left.g^{(3)}\right)$. If $S L D$ proposes $g^{(1)}$ or $g^{(2)}$, then $P S L$ is involved in the negotiations. Suppose that $S L D$ offers $g^{(1)}$. If $P S L$ says 'yes', then the game is over and the result is $\left(g^{(1)}, 1\right)$. However, if $P S L$ rejects $g^{(1)}$, it has to submit its offer in period 2. Since PSL is a member of two governments $\left(g^{(1)}\right.$ and $\left.g^{(2)}\right)$ and $g^{(1)}$ has already been proposed in period 1,PSL will propose $g^{(2)}$, which will be either accepted or rejected by $S L D$. Again, accepting $g^{(2)}$ implies the result $\left(g^{(2)}, 2\right)$, and rejecting causes $S L D$ to offer $g^{(3)}$ in period 3 which has to be accepted by $P O$. The parties reach then the result $\left(g^{(3)}, 3\right)$. Suppose now that $S L D$ proposes $g^{(2)}$ in period 1 . If $P S L$ says 'yes', the result is $\left(g^{(2)}, 1\right)$, otherwise $P S L$ offers $g^{(1)}$ in period 2. Accepting this offer by $S L D$ gives the result $\left(g^{(1)}, 2\right)$, and rejecting it causes that $S L D$ proposes $g^{(3)}$ in period 3 which has to be accepted by $P O$. Then we have the result $\left(g^{(3)}, 3\right)$. 
By analogy, we construct the games with $P O$ or $P S L$ starting the negotiations. One can prove the following fact.

Fact 4.1 For Game A, given Table 6, there are the following subgame perfect equilibria:

1. If $S L D$ is the first proposer, then there is only one subgame perfect equilibrium $\left(f_{1}, f_{2}, f_{3}\right)$ which looks as follows:

- $f_{1}$-strategy of SLD:

In period 1 , it proposes $g^{(3)}$.

In period 2, it accepts neither $\mathrm{g}^{(1)}$ nor $\mathrm{g}^{(2)}$.

In period 3, it proposes $g^{(3)}$.

- $f_{2}$-strategy of PO: When $g^{(3)}$ is proposed, it always says 'yes'.

- $f_{3}$-strategy of PSL:

In period 1 , it accepts both $g^{(1)}$ and $g^{(2)}$.

In period 2 , if $g^{(1)}$ has been proposed in period 1 , it submits $g^{(2)}$;

if $g^{(2)}$ has been proposed in period 1 , it proposes $g^{(1)}$.

This subgame perfect equilibrium leads to the result $\left(g^{(3)}, 1\right)$, that is, SLD proposes (in period 1$)$ to create the government $g^{(3)}$, and PO agrees.

2. If PO is the first proposer, then there is only one subgame perfect equilibrium $\left(f_{1}, f_{2}, f_{3}\right)$ :

- $f_{1}$-strategy of SLD:

In period 1 , it accepts $g^{(3)}$.

In period 2, it proposes $g^{(1)}$.

In period 3, it always accepts an offer.

- $f_{2}$-strategy of PO: In period 1 , it proposes $g^{(3)}$.

- $f_{3}$-strategy of PSL:

In period 2, it accepts $g^{(1)}$, but it rejects $g^{(2)}$.

In period 3 , if $g^{(1)}$ has been proposed in period 2, it submits $g^{(2)}$;

if $g^{(2)}$ has been proposed in period 2, it proposes $g^{(1)}$.

This subgame perfect equilibrium leads to the result $\left(g^{(3)}, 1\right)$, that is, PO proposes (in period 1$)$ to create the government $g^{(3)}$, and $S L D$ agrees.

3. If PSL is the first proposer, then there are two subgame perfect equilibria $\left(f_{1}, f_{2}, f_{3}\right)$ and $\left(f_{1}, f_{2}, f_{3}^{\prime}\right)$, where:

- $f_{1}$-strategy of SLD:

In period 1 , it does not accept either $g^{(1)}$ or $g^{(2)}$.

In period 2, it always proposes $g^{(3)}$.

- $\quad f_{2}$-strategy of PO: In period 2, it always accepts $g^{(3)}$.

- $f_{3}$-strategy of PSL:

In period 1, it proposes $g^{(1)}$.

In period 2, it accepts both $g^{(1)}$ and $g^{(2)}$.

- $f_{3}^{\prime}$-strategy of PSL:

In period 1, it proposes $g^{(2)}$.

In period 2, it accepts both $g^{(1)}$ and $g^{(2)}$.

Both subgame perfect equilibria lead to the result $\left(g^{(3)}, 2\right)$.

Proof For each case analyzed, we construct the extensive form of the game and then, using formulas (7) and (8), and Table 6, we use backward induction. Starting from the end points of the game and going backwards to its beginning, we choose the best response of a given player in each information set.

Let us consider examples of Game $\mathrm{A}^{\prime}$ with some bargaining costs. We will see that introducing higher costs frequently changes the number and the form of subgame perfect equilibria as 
well as the result of the game. Using again backward induction, one can easily prove the following fact.

Fact 4.2 For Game A', given Table 6, there are the following subgame perfect equilibria:

1. If $S L D$ is the first proposer, $c_{2}=\frac{2}{3}$, and $c_{3}>\frac{2}{3}$, then there are two subgame perfect equilibria $\left(f_{1}, f_{2}, f_{3}\right)$ and $\left(f_{1}, f_{2}, f_{3}^{\prime}\right)$ which look as follows:

- $f_{1}$-strategy of SLD:

In period 1, it proposes $g^{(3)}$.

In period 2, it accepts both $g^{(1)}$ and $g^{(2)}$.

In period 3 , it proposes $g^{(3)}$.

- $f_{2}$-strategy of PO: When $g^{(3)}$ is proposed, it always says 'yes'.

- $f_{3}$-strategy of PSL:

In period 1 , it accepts both $g^{(1)}$ and $g^{(2)}$.

In period 2, if $g^{(1)}$ has been proposed in period 1 , it submits $g^{(2)}$;

if $g^{(2)}$ has been proposed in period 1, it proposes $g^{(1)}$.

- $f_{3}^{\prime}$-strategy of PSL:

In period 1 , it accepts $g^{(1)}$, but it rejects $g^{(2)}$.

In period 2 , if $g^{(1)}$ has been proposed in period 1 , it submits $g^{(2)}$;

if $g^{(2)}$ has been proposed in period 1 , it proposes $g^{(1)}$.

Both subgame perfect equilibria lead to the result $\left(g^{(3)}, 1\right)$.

2. If $P O$ is the first proposer, $c_{2}>0$ is arbitrary, and $c_{3}>\frac{2}{3}$, then there is only one subgame perfect equilibrium $\left(f_{1}, f_{2}, f_{3}\right)$ :

- $f_{1}$-strategy of SLD:

In period 1 , it accepts $g^{(3)}$.

In period 2, it proposes $g^{(2)}$.

In period 3, it always accepts an offer.

- $f_{2}$-strategy of PO: In period 1 , it proposes $g^{(3)}$.

- $f_{3}$-strategy of PSL:

In period 2, it accepts both $g^{(1)}$ and $g^{(2)}$.

In period 3 , if $g^{(1)}$ has been proposed in period 2, it submits $g^{(2)}$;

if $g^{(2)}$ has been proposed in period 2, it proposes $g^{(1)}$.

This subgame perfect equilibrium leads to the result $\left(g^{(3)}, 1\right)$.

3. If PSL is the first proposer, and $c_{2}>\frac{2}{3}$, then there is only one subgame perfect equili$\operatorname{brium}\left(f_{1}, f_{2}, f_{3}\right)$ :

- $f_{1}$-strategy of SLD :

In period 1 , it accepts both $g^{(1)}$ and $g^{(2)}$.

In period 2, it always proposes $g^{(3)}$.

- $f_{2}$-strategy of PO: In period 2, it always accepts $g^{(3)}$.

- $f_{3}$-strategy of PSL:

In period 1 , it proposes $g^{(1)}$.

In period 2, it accepts both $g^{(1)}$ and $g^{(2)}$.

This subgame perfect equilibrium leads to the result $\left(g^{(1)}, 1\right)$.

Proof Similarly as in the proof of Fact 4.1. For each case considered, the extensive form of the game is constructed. Next, using formula (9), and Table 6, we use backward induction.

Let us compare the games analyzed. Note that the subgame perfect equilibrium strategies of $S L D$ and $P S L$ are different in the games $\mathrm{A}$ and $\mathrm{A}^{\prime}$, with $S L D$ as first proposer. Introducing even very high bargaining costs cannot change the result of the game. In both cases, the 
result will be always $\left(g^{(3)}, 1\right)$. But it does change the form and the number of subgame perfect equilibria. Game A has only one subgame perfect equilibrium, but Game A' has two subgame perfect equilibria. In case $P S L$ is the first proposer, introducing higher bargaining costs may additionally change the result. Game A with $P S L$ proposing first, has two subgame perfect equilibria, both leading to the result $\left(g^{(3)}, 2\right)$. If we assume that $c_{2}>\frac{2}{3}$, then Game $\mathrm{A}^{\prime}$ has only one subgame perfect equilibrium, leading to the result $\left(g^{(1)}, 1\right)$.

Note that in Game A with PSL as the first proposer, both subgame perfect equilibria give the stable government $g^{(3)}$ which has the lowest (even negative) value for $P S L$. So, sometimes a subgame perfect equilibrium may lead to the worst result for the first proposer, as is shown in this case. If $c_{2}>\frac{2}{3}$, then the situation of $P S L$ changes completely, because then the best government for $P S L$ is reached, and already in period 1.

Remark 4.1 Note that in game $\mathrm{A}^{\prime}$ with $P O$ as first proposer, $c_{2}>0$ and $c_{3}>\frac{2}{3}$, the subgame perfect equilibrium outcome is $\left(g^{(3)}, 1\right)$, the worst possible outcome for $P O$. But with $P S L$ as first proposer and $c_{2}>\frac{2}{3}$, the subgame perfect equilibrium outcome is $\left(g^{(1)}, 1\right)$, the best possible outcome for $P O$. So, a party may be better off when it is not the first proposer.

\subsection{Games B, B', C and $\mathrm{C}^{\prime}$}

Fact 4.3 For Game B described, given Table 6, if $\overline{N^{S G}}=(S L D, P O, P S L)$, then there are 256 subgame perfect equilibria, but each of them leads to the result $\left(g^{(1)}, 1\right)$, that is, $S L D$ proposes $g^{(1)}$ in period 1 , and both PO and PSL agree.

Since Game B can have so many subgame perfect equilibria, in principle, we would not recommend it to play. There are two reasons for such a huge number of equilibria in our Game B: responses of $P O$ in period 1, and responses of $S L D$ in period 2. In period 1, if $S L D$ proposes $g^{(2)}$, then both responses 'yes' and 'no' give the same result for $P O$. Similarly, if $S L D$ offers $g^{(3)}$, then both accepting and rejecting lead to the same result for $P O$. Hence, we have already $2^{2}$ possibilities for a strategy of $P O$. If either $g^{(1)}$ or $g^{(2)}$ has been proposed in period 1, then in each subgame starting in period 2 with either $P O$ or $P S L$ proposing an offer, if $g^{(3)}$ is proposed in period 2, then both saying 'yes' and 'no' by $S L D$ give the same result for $S L D$. There are four such subgames. Similarly, if $g^{(3)}$ has been proposed in period 1, then in each subgame starting in period 2 with either $P O$ or $P S L$ proposing, if $g^{(2)}$ is offered in period 2, then both the acceptance and the rejection of $g^{(2)}$ give the same result for $S L D$. There is one such a subgame perfect equilibrium with $P S L$ proposing, and one such a subgame perfect equilibrium with $P O$ offering. Hence, since there are together six such subgames, we have $2^{6}$ possibilities for a strategy of $S L D$. Hence, together we get $2^{2} \times 2^{6}=256$ subgame perfect equilibria.

Introducing very high bargaining costs may completely change the situation. Using backward induction, one can show that

Fact 4.4 For Game $B^{\prime}$ described, given Table 6 , if $\overline{N^{S G}}=(S L D, P O, P S L)$ and $c_{2}=c_{3}=5$, then there is only one subgame perfect equilibrium, and it leads to the result $\left(g^{(3)}, 1\right)$, that is, SLD proposes $g^{(3)}$ in period 1 , and both PO and PSL agree.

Remark 4.2 In game A, party $P O$ is involved in the chosen government $g^{(3)}$. But $P O$ is better off in game $\mathrm{B}$, in which also $P S L$, not belonging to $g^{(3)}$, participates in the negotiations, since in game $\mathrm{B}$ with order $(S L D, P O, P S L)$ the subgame perfect equilibria lead to the result $\left(g^{(1)}, 1\right)$, which is the best possible result for $P O$. So, a party involved in a chosen government may be better off if parties not belonging to this government also participate in the negotiations. 
Fact 4.5 For Game C described, given Table 6, if $\overline{N^{S G}}=(S L D, P O, P S L)$ or $\overline{N^{S G}}=$ ( $S L D, P S L, P O)$, then there is only one subgame perfect equilibrium $\left(f_{1}, f_{2}, f_{3}\right)$, which leads to the result $\left(g^{(1)}, 1\right)$.

Fact 4.6 For Game $C^{\prime}$ with $c_{2}>\frac{2}{3}$, and $0<c_{3}<\frac{1}{3}$, given Table 6, if $\overline{N^{S G}}=(S L D, P O$, $P S L)$ or $\overline{N^{S G}}=(S L D, P S L, P O)$, then there is only one subgame perfect equilibrium $\left(f_{1}, f_{2}, f_{3}\right)$, which leads to the result $\left(g^{(3)}, 1\right)$.

Remark 4.3 In game C with $S L D$ as the (only) party that can make proposals, the subgame perfect equilibrium outcome is $\left(g^{(1)}, 1\right)$, which is the best possible outcome for $P S L$ that is a member of this government, while $g^{(1)}$ is the worst possible outcome for $S L D$. So, it may be better for a party if another party makes the offers.

\subsection{What is Best for the Strongest Party?}

Let us analyze the games considered with respect to the 'strongest' party, that is $n_{1}$ in the ordered list $\overline{N^{C G}}$. Table 7 presents the comparison of all six games analyzed. For Games $\mathrm{A}^{\prime}$, $\mathrm{B}^{\prime}$, and $\mathrm{C}^{\prime}$, we also add examples of the bargaining costs $c_{2}$ and $c_{3}$ for which these games lead to the results mentioned.

Note that Table 7 mentions only the results of the games, and it does not present the precise forms of the subgame perfect equilibria. This is why the costs mentioned in Table 7 are more general than those mentioned in Facts 4.2, 4.4, and 4.6.

One can conclude from the analysis of Table 7, that Game A is one of the best ways for $S L D$ to reach its best result $\left(g^{(3)}, 1\right)$, that is, its most valuable government $g^{(3)}$ already in period 1. One may construct an example, in which Game $C^{\prime}$ is the only game leading to the best result for party $n_{1}$. Nevertheless, in our example, it is Game A which leads to $\left(g^{(3)}, 1\right)$. Moreover, in our example, all Games $\mathrm{A}^{\prime}, \mathrm{B}^{\prime}$, and $\mathrm{C}^{\prime}$, lead to the result $\left(g^{(3)}, 1\right)$. Moreover, in Game $\mathrm{A}^{\prime}$, for instance, both costs $c_{2}$ and $c_{3}$ may be arbitrary, and Game $\mathrm{A}^{\prime}$ will always give the result $\left(g^{(3)}, 1\right)$, no matter how high $c_{2}$ is. Game B gives the result $\left(g^{(1)}, 1\right)$ which is the best result for both $P O$ and $P S L$. In fact, for $P O$ and $P S L$, government $g^{(3)}$ has the smallest value from among the values of all stable governments. For Game $\mathrm{C}^{\prime}$, the bargaining costs are smaller than the ones for Game $\mathrm{B}^{\prime}$.

Table 7 Comparison of bargaining games with $\overline{N^{C G}}=(S L D, P O, P S L)$ and $U=\left(U_{S L D}, U_{P O}, U_{P S L}\right)$

\begin{tabular}{lllll}
\hline Game & Costs & Result & Parties involved & $U(g)$ \\
\hline Game A & condition (8) & $\left(g^{(3)}, 1\right)$ & $S L D, P O$ & $\left(\frac{8}{3}, \frac{4}{3},-\frac{8}{3}\right)$ \\
Game A' & $c_{2}>0$-arbitrary & $\left(g^{(3)}, 1\right)$ & $S L D, P O$ & $\left(\frac{8}{3}, \frac{4}{3},-\frac{8}{3}\right)$ \\
& $c_{3}>0$-arbitrary & & & $(2,2,2)$ \\
Game B & condition (8) & $\left(g^{(1)}, 1\right)$ & $S L D, P S L$ & $\left(\frac{8}{3}, \frac{4}{3},-\frac{8}{3}\right)$ \\
Game B & $c_{2}>\frac{14}{3}$ & $\left(g^{(3)}, 1\right)$ & $S L D, P O$ & $(2,2,2)$ \\
Game C & $c_{3}>0$-arbitrary & & & $\left(g^{(1)}, 1\right)$ \\
Game C & condition (8) & $\left(g^{(3)}, 1\right)$ & $S L D, P S L$ & $\left.\frac{4}{3},-\frac{8}{3}\right)$ \\
& $c_{2}>\frac{2}{3}$ & & &
\end{tabular}




\section{Conclusions}

In this paper, we applied bargaining theory to a new model of coalition formation. The central notions of this model are the notions of a feasible government and a stable government. In order to choose one stable government in case there is more than one (or one feasible government if there is no stable one and several feasible ones), we introduced negotiations between parties, resulting in the choice of one stable (feasible) government. We defined several bargaining games and investigated the subgame perfect equilibria of these games. In Proposition 3.2 we gave conditions under which the strongest party $\left(n_{1} \in N^{C G}\right)$ can achieve its best possible result by playing an appropriate bargaining game. As a consequence we found that there is always a bargaining game in which all subgame perfect equilibria lead to the best possible outcome for the strongest party $n_{1}$. We applied the coalition formation model and the bargaining games to the Polish Parliament after the 2001 elections with respect to some fictitious policy issues. For this example, we compared all bargaining games.

Our example shows that in the subgame perfect equilibrium outcome, depending on the bargaining game,

- a party may be better off when it is not the first proposer (Remark 4.1);

- a party involved in a chosen government may be better off if parties not belonging to this government also participate in the negotiations (Remark 4.2);

- it may be better for a party if another party makes the offers (Remark 4.3).

Acknowledgements We are very grateful to two anonymous referees for very valuable suggestions which improved the paper a lot, both in contents and readability.

\section{References}

Austen-Smith D, Banks J (1988) Elections, coalitions, and legislative outcomes. Am Polit Sci Rev 82:405-422 Austen-Smith D, Banks J (1990) Stable governments and the allocations of Policy Portfolios. Am Polit Sci Rev 84:891-906

Axelrod R (1970) Conflict of interest; a theory of divergent goals with applications to politics. Markham, Chicago

Baron DP, Ferejohn J (1989) Bargaining in legislatures. Am Polit Sci Rev 83:1181-1206

de Swaan A (1973) Coalition theories and cabinet formations. Elsevier, Amsterdam

de Vries M (1999) Governing with your closest neighbour: an assessment of spatial coalition formation theories. Ph.D.thesis, Nijmegen University. Print Partners Ipskamp

Diermeier D, Merlo A (2000) Government turnover in parliamentary democracies. J Econ Theory 94:46-79

Diermeier D, Merlo A (2004) An empirical investigation of coalitional bargaining procedures. J Public Econ 88:783-797

Diermeier D, Eraslan H, Merlo A (2003) A structural model of government formation. Econometrica 71:27-70

Fishburn PC, Rubinstein A (1982) Time preferences. Int Econ Rev 23:667-694

Grofman B (1982) A dynamic model of protocoalition formation in ideological N-space. Behav Sci 27:77-90

Kahan J, Rapoport A (1984) Theories of coalition formation. Lawrence Erlbauw Associates Publishers

Kirchsteiger G, Puppe C (1997) On the formation of political coalitions. J Instit Theor Econ 153:293-319

Laver M, Shepsle K (1996) Making and breaking governments; cabinet and legislatures in parliamentary democracies. Cambridge University Press

Mas-Colell A, Whinston MD, Green JR (1995) Microeconomic theory. Oxford University Press

Merlo A (1997) Bargaining over governments in a stochastic environment. J Polit Econ 105:101-131

Morelli M (1999) Demand competition and policy compromise in legislative bargaining. Am Polit Sci Rev 93:809-820

Osborne MJ, Rubinstein A (1990) Bargaining and markets. Academic Press, San Diego

Osborne MJ, Rubinstein A (1994) A course in game theory. MIT Press, Cambridge Mass

Peleg B (1981) Coalition formation in simple games with dominant players. Int J Game Theory 10:11-33 
Roubens M, Rusinowska A, de Swart H (2006) Using MACBETH to determine utilities of governments to parties in coalition formation. Eur J Oper Res 172:588-603

Rubinstein A (1982) Perfect equilibrium in a bargaining model. Econometrica 50:97-109

Rusinowska A, de Swart H, van der Rijt JW (2005) A new model of coalition formation. Soc Choice Welfare 24:129-154

Schofield N (1993) Political competition and multiparty coalition governments. Eur J Polit Res 23:1-33

Selten R (1975) Reexamination of the perfectness concept for equilibrium points in extensive games. Int $\mathbf{J}$ Game Theory 4:25-55

van Deemen A (1991) Coalition formation in centralized policy games. J Theor Polit 3:139-161

van Deemen A (1997) Coalition formation and social choice. Kluwer Academic Publishers, Dordrecht

van der Rijt JW (2000) An alternative model on the formation of political coalitions. Masters thesis, Tilburg University 